\title{
Análise do discurso midiático do projeto "acolhida na colônia” na atividade do agroturismo em Santa Rosa de Lima - SC
}

\author{
Felipe Borborema Cunha Lima1 \\ Universidade do Vale do Itajaí-SC
}

Luana de Sousa Oliveira ${ }^{2}$

Universidade do Vale do Itajaí-SC

Yolanda flores e Silva ${ }^{3}$

Universidade do Vale do Itajaí-SC

\begin{abstract}
Resumo: Consideramos a importância de analisar o discurso midiático sobre o agroturismo em Santa Rosa de Lima, observando se a imagem propagada pelos meios de comunicação apresenta-se uniforme ou com variações sobre a mesma e dessa forma criando várias múltiplas imagens da localidade, bem como de seus moradores. Os procedimentos metodológicos adotados tiveram como base a pesquisa qualitativa com abordagem exploratória, através da coleta de dados bibliográfico e documental, de material midiático, utilizados como objeto de divulgação do modelo de agroturismo na região nos últimos cinco anos. Para análise deste material, utilizamos técnicas de análise de discurso do Modelo de Cooperação Textual de Umberto Eco. Ao final oferecemos os discursos existentes das distintas imagens do município pesquisado.
\end{abstract}

Palavras-chave: Turismo; Agroturismo; Discurso Midiático; Santa Rosa de Lima.

Title: Analysis of Media Discourse of the Project “Accepted in the Colony” in the Activity of Agritourism in Santa Rosa de Lima - SC

Abstract: The subject of this article is the architectural and landscape complex of Igarassu, more specifically the interrelationships between cultural heritage, tourism and public management in the historic site. The field work showed that the current pattern of tourism is an instrument of devaluation and deterioration of this heritage, leaving reduced benefits to the city. This results from the external control of the flow of tourists and visitors, as well as the lack of effective public control and regulation by local government. Given the nature of the tourism market, specifically the agencies and tour guides, and public management in Igarassu, relevant changes in the interrelationships cited above are assessed as unlikely to happen, at least in the short and medium term.

Keywords: Cultural heritage; Cultural tourism; Cultural and touristic public management; Receptive tourism agencies; Tour guides; Socio-economic and cultural impacts.

1 Turismólogo / Mestre em Turismo e Hotelaria pela UNIVALI - felipebcl2@hotmail.com 2 Turismóloga / Mestre em Turismo e Hotelaria pela UNIVALI - luana436@hotmail.com

3 Docente/Pesquisadora no Programa de Pós-Graduação em Turismo e Hotelaria /Mestrado Acadêmico da Universidade do Vale do Itajaí - UNIVALI; yolanda@univali.br 


\section{Introducción}

A atividade turística em espaço rural vem se desenvolvendo cada vez mais no Brasil e no mundo. De uma corrente que busca oposição ao chamado turismo convencional surge o que Tulik (2000) denomina de turismo alternativo, que de acordo a autora, emerge como uma necessidade do homem moderno frente ao cotidiano urbano industrializado, com muitas exigências, estresse diário em função das novas estruturas econômicas, o desenvolvimento acelerado das grandes cidades e centros urbanos, além dos valores captados pelo movimento ambientalista (Ruschmann, 1997).

O turismo no espaço rural, nasceu da idealização de muitas pessoas, que vislumbram o campo ou meio rural de forma especial seja por razões culturais (origem na sociedade rural agrária) ou no reconhecimento de que este ambiente e seu povo atende à necessidade mais básica do ser humano, o alimento (Swarbooke, 2000).

Contudo, não foram somente as razões citadas acima as que determinaram o desenvolvimento do turismo no espaço rural. Devemos ressaltar que as iniciativas de realizar as atividades de turismo rural, tiveram como objetivo inicial, favorecer as propriedades rurais, visando o combate ao êxodo rural, complementar a renda das propriedades rurais, a proteção da natureza entre outras possibilidades, e não a simples e pura ocupação do tempo livre, através do turismo (Tulik, 2003).

Neste contexto de "venda" do espaço rural observamos, que a mídia possui um caráter de fundamental importância no que se refere à criação de 'necessidades' do consumo de determinados produtos ou serviços. Tal afirmação mostra como podemos ser invadidos por idéias e sugestões, inclusive sobre o tipo de turismo que devemos fazer. Nesta época de consumo, na qual a sociedade é invadida por uma constante oferta midiática, possibilitando criar a ilusão dos sentidos, numa dinâmica que levam os símbolos a tomarem o lugar das coisas que consideramos verdadeiras em nosso cotidiano (Carmo, 2006).

A partir deste olhar, é que começamos a sentir a necessidade de entender o discurso apresentado pela mídia sobre o desenvolvimento da atividade de agroturismo em Santa Rosa de Lima. Esta forma de turismo consolida-se neste município em 1999, após a criação do projeto "Acolhida na Colônia". A proposta segue o modelo francês da associação francesa Accueil Paysan, tornando-se uma referência para outros municípios, atraindo desta forma não apenas turistas, mas, também a mídia, que viu na organização dos agricultores um fenômeno de interesse, visto que estes apresentavam sua proposta de turismo como um avanço diante de outras formas de se fazer turismo.

\section{Justificativa e problema de pesquisa}

Considerando o avanço da realidade virtual (e até mesmo a não virtual representada por revistas e jornais impressos), observamos que os produtos oferecidos por este tipo de mídia, de uma forma geral são apresentados através de publicidades. Este formato de apresentação une uma série de elementos de atração tão avançados, que uma pessoa pode adquirir a sensação de experimentação de um produto ou serviço oferecido, mesmo quando não os adquire. Este fenômeno demonstra o poder da mídia sobre a capacidade de chegar à psique de uma pessoa e inclusive induzi-la a sentir necessidades de compra e uso de determinadas ofertas (Nielsen, 2002). Dessa forma, a partir da perspectiva acima nosso problema de pesquisa está representado na questão abaixo, seguida dos objetivos que nortearam nosso estudo: Qual é a imagem divulgada no discurso midiático sobre a Acolhida na Colônia no contexto do desenvolvimento da atividade do agroturismo em Santa Rosa de Lima - SC? O objetivo geral para responder a esta questão foi o de: analisar o discurso midiático da mídia impressa, televisiva, eletrônica e no formato publicitário, que divulga o projeto "Acolhida na Colônia", enquanto atividade de Agroturismo em Santa Rosa de Lima - SC.

Para chegarmos ao objetivo proposto, optamos por utilizar a metodologia qualitativa, que de acordo com Turato (2005) é aquela que objetiva entender o significado individual ou coletivo dos fenômenos, manifestações, ocorrências, fatos, eventos, vivências, idéias e sentimentos. Em nosso estudo, considerando os objetivos propostos, tivemos duas etapas de coleta e análise dos dados: Etapa 1 - Coleta documental: com a seleção de textos impressos, eletrônicos e televisivos; leituras / fichamentos; e categorizações do tipo de produção selecionada; Etapa 2 - Análise documental: Análise de conteúdo / discurso de acordo com o modelo de cooperação textual de Umberto Eco (1986), realizado segundo uma adaptação de Silva (1999). Apresentamos em seguida, uma síntese desta adaptação e explicamos cada passo realizado considerando o tipo de material que estaremos coletando: material escrito e oral.

Neste modelo o discurso e o conteúdo são analisados como uma estrutura narrativa. Eco (1986) distingue os textos classificando-os em textos narrativos com narrativa natural e narrativa artificial, onde as duas constituem exemplos da descrição de ações, mas a primeira se refere aos eventos apresentados como eventos realmente acontecidos (como notícias do dia nos jornais); já a narrativa artificial refere-se às pessoas e fatos atribuídos a mundos possíveis. Neste ínterim, é relevante dar os significados de cada item do modelo de cooperação 
textual que será usado em nosso estudo para análise dos dados. A Manifestação Linear consiste num resumo do texto, na forma de documento escrito ou oral; As Circunstâncias de Enunciação têm relação com a origem do texto, seus autores e o contexto histórico e literário dos mesmos, a inserção da obra e sua relevância dentro da temática estudada; Os Códigos e Subcódigos são classificados em sub-categorias, iniciando pelo Dicionário de Base, termos caracterizados como substantivos, investidos de propriedades e elementos relacionados à temática estudada e os seus objetivos. Hipercodificação Ideológica que são lexemas que possuem juízo de valor e crenças dos autores; Estruturas Discursivas que dizem respeito às idéias centrais do texto narrativo e se relacionam com os objetivos que escolhemos para dar vida à proposta de pesquisa construída por nós. Estruturas Narrativas que surgem como parte da seqüência narrativa do texto, em ordem cronológica e tópicos sumarizados. São macroproposições narrativas que nos mostram como os discursos vão surgindo no texto, que justificativas são fornecidas para os mesmos e que significados e sentidos dão as temáticas em discussão. As Estruturas Ideológicas que fazem uma apresentação dos papéis sugeridos e dirigidos ao leitor-modelo; Finalmente temos as Estruturas de Mundo que com suas matrizes de mundo mostram as possibilidades e as acessibilidades entre mundos e o reconhecimento de atitudes proposicionais relacionadas ao tema estudado.

Dessa forma, o modelo de cooperação textual, permite uma forma de estudo que pode ser considerada intermediária entre a análise da teoria literária que admiti uma infinidade de interpretações para qualquer texto e a hermenêutica normativa, cujas interpretações são condicionadas as intenções do autor, possibilitando detectar os signos presentes nos discursos midiáticos e consequentemente a imagem que é divulgada do agroturismo no município.

\section{Mídia e Turismo}

Mídia é um termo derivado do latim que tem por significado 'meio'. No contexto atual, a mídia participa do planejamento, negociação, execução e controle da veiculação de uma campanha ou ainda os meios ou veículos de comunicação. A função do profissional da mídia é planejar onde, para quem, quando, quanto, por que e como a mensagem deverá ser veiculada; negociar sua colocação nos veículos mais adequados para o produto pelo custo competitivo; executar exatamente como foi planejado e exercer rigoroso controle do que está sendo veiculado (Tahara, 1998).

A mídia e a comunicação de massa são cada vez mais presentes na vida das pessoas, sendo responsável por grande parte das informações e dos entretenimentos utilizados pela população, exercendo um impacto maior à medida que ocorre o desenvolvimento da tecnologia e a diminuição das fronteiras, frente ao processo de globalização. A mídia é responsável atualmente por representar e criar a imagem de todo e qualquer produto e serviço disponível no mercado.

Com a mídia, o turismo amplia seu universo de divulgação e venda do mito do deslocamento e a busca do lugar perfeito, belo e ideal. Os panfletos, revistas e filmes de promoção turística apropriam-se de ângulos e efeitos, a ponto de criarem a imagem da terra prometida, do paraíso perdido. Além disto, as pessoas contam com a mídia para receber informações sobre as ações políticas do local, prováveis problemas ecológicos, econômicos e sociais para decidir ou rejeitar uma destinação turística. O que foi descrito por Kotler como sendo a idéia da imagem: "a imagem mercadológica de uma destinação turística é um conjunto de idéias correntes sobre a localidade" (Kotler, 1995, p. 151).

Entendendo a importância e a força que a mídia causa sob os destinos turísticos, Ruschmann (1990, p. 70) afirma que: "a propaganda turística é considerada uma atividade que influência e se esforça em persuadir e habituar as pessoas a viajar, propondo-lhes motivos que despertem o desejo de conhecer um determinado local".

É importante, porém ressaltar-se que essa imagem pode muitas vezes ser manipulada para beneficiar ou prejudicar o local, envolvendo várias questões éticas e morais. Obviamente os problemas e defeitos de um local não podem ser esquecidos, contudo os responsáveis pelo marketing, agem de forma a exaltar os atrativos de um destino, no intuito de minimizar os problemas relacionados à imagem do local, pois segundo Wild, (2004, p. 42) "quando o turista decide viajar ele compra antes de tudo uma imagem".

Através dessa ótica entendemos que toda publicação tem um recorte a apresentar ao leitor, não apenas ligado a eventos culturais, mas também a todo um conjunto de olhares sobre as tendências do momento em relação ao passado. Neste foco incluem-se perdas e ganhos, sendo esse recorte então ponto determinante na decisão de escolha por parte dos turistas que podem ser influenciados positiva ou negativamente (Piza, 2003).

Nesse ponto observamos que a atividade turística e os meios de comunicação estão cada vez mais interligados. Nesse âmbito a mídia massiva apresenta o foco principal para a unidade desse trabalho, pois "todo texto caracteriza-se pela textualidade (tessitura), rede de relações que fazem com que um texto seja um texto (e não uma simples somatória de frases), revelando uma conexão entre as intenções, as idéias e as unidades lingüísticas que o compõem” (Koch, 1984, p. 21). Em ou- 
tras palavras a comunicação de massa funciona como um gigantesco processador de imagens, textos e sons, que inibe e intensifica os desejos e as necessidades do público/turista.

Exemplo desse efeito da mídia sobre o comportamento humano é apresentado no Modelo de Comunicação de Lombardi, em que um indivíduo pode vivenciar um determinado evento de duas maneiras, a primeira é fazendo parte do mesmo, ou seja, através da experiência própria com o fato, criando suas referências e relações e assim tomando para si uma verdade sobre o ocorrido; a outra maneira ocorre através da mídia de massa, ou seja, os meios de comunicação relatam os fatos e acontecimentos gerando uma nova versão do ocorrido criando uma imagem e consequentemente uma nova verdade, que será absorvida pelo espectador. Nestas circunstâncias, o evento e a mídia encontram־se no mesmo nível, numa indicação de que caso o evento não seja transmitido pelos meios de comunicação para as pessoas que não vivenciarão o evento, será como se ele não estivesse existido ou acontecido, pois é a soma de uma ação e da percepção dessa ação que resulta na opinião pública (Nielsen, 2002).

Contudo não podemos nos esquecer que antes de tudo o meio de comunicação, em especial o jornal, como afirma Noblat (2003), são responsáveis por transmitir o entendimento, além das informações e do conhecimento, afinal antes de ser um negócio deve ser visto como um serviço público e dessa conduta resulta a confiança pública creditada nele. Esse aspecto também é ressaltado por Kovach e Rosentiel (2003) que apresentam como principal obrigação do jornalismo o compromisso com a verdade, de caráter investigativo e sempre mantendo imparcialidade aquilo que informa.

O jornalismo, porém está cada vez mais distante desse modelo utópico proposto por alguns autores, de ser um produto voltado apenas à investigação e a informação, originando um produto específico capaz de atrair verbas subsidiadas por empresas privadas que visam interesses particulares, frente à ação da demanda de mercado, originando um jornalismo contaminado pelo discurso publicitário.

Um tipo de jornalismo conhecido como jornalismo publicitário e de relações públicas semelhantes ao jornalismo de denuncia, mas que resulta em dossiers

(muitas vezes jornalisticamente preparados) que são oferecidos aos jornalistas com a finalidade de apresen-

tação de produtos e serviços ou visando à promoção

de pessoas, organizações em geral e instituições. Por vezes, além dos dossiers, são facultadas aos jornalistas visitas, viagens, amostras, testes, etc. (sousa, 2004, p. 31).
O resultado dessa mudança é um novo produto jornalístico submisso à divulgação e ao consumismo, que já não possui o mesmo interesse pela imparcialidade da informação. Caracterizado pela predominância da imagem, com priorização da cor, letras garrafais e fotos hiperdimensionadas, surge uma publicidade travestida de jornalismo. Isto significa um "jornal sem palavras", fruto da competição cada vez mais acirrada com a mídia audiovisual, incluindo no discurso jornalístico a natureza persuasiva da publicidade, como se esse fosse um elemento natural, originando um produto capaz de estimular o consumidor por meio de uma teia de símbolos, ícones e imagens (Marshall, 2003, p. 27).

Todo esse processo que atingiu os meios de comunicação em especial o jornalismo teve sua origem no surgimento de novas tecnologias, a globalização e a acumulação de funções. O melhor exemplo é a internet, que dissociou o jornalismo de suas fronteiras geográficas e, portanto distanciando de suas comunidades de origem, originando empresas sem fronteiras. Somadas a globalização os conteúdos foram modificados frente ao mais recente requisito, o benefício econômico (Kovach e Rosentiel 2003).

Os cadernos de turismo dos jornais impressos tornam-se de acordo com Piovesan (2005) o mais evidente exemplo desse fenômeno, em que o jornalismo e a publicidade coexistem de maneira tão harmoniosa, que por muitas vezes se fundem e se confundem como uma só, interagindo na produção dos sentidos e não mais de um discurso jornalístico. Esse diálogo, ainda de acordo com o mesmo autor, apresenta-se por meio de utilização de releases preparados pelo trade turístico como matéria jornalística, com construções sintáticas e discursos rápidos com o objetivo de causar impacto aos leitores com alto poder aquisitivo, tirando proveito dos recursos gráficos e de uma privilegiada linguagem visual, tendo a imagem como foco principal do novo formato.

Estas mudanças sofridas pelo jornal ocorrem também devido a forte concorrência com os meios de comunicação audiovisual, levando o mundo impresso a recorrer das mesmas ferramentas para se manter na disputa pela audiência originando um festival de signos e ícones que pode ser resumido em uma equação simples: "quanto mais o jornal for parecido com um videoclipe, maior a eficácia do produto" (Marshall, 2003, p. 49).

Por outro lado, existem autores que enxergam esse processo de maneira positiva. Os recursos visuais são apresentados como uma tendência correta e conveniente para a informação, desde que observado a ordem de primeiro estar a serviço da informação e em segundo lugar do embelezamento do jornal. O objetivo é informar, portanto é admissível até mesmo suprimir um tex- 
to quando uma ilustração comunicar melhor (Noblat, 2003).

Para Castells (1999) a maioria dos estímulos simbólicos que atingem o ser humano atualmente vem dos meios de comunicação, isso se dá por vivermos em um ambiente midiático. Aposta-se na idéia de que a contemplação de imagens pode vir a despertar um conjunto de percepções, favorecendo um conhecimento aproximado do imaginário coletivo, em perspectiva a uma interpretação plural da cultura apresentada.

Os símbolos, ícones e mitos consolidados pela difusão deste tipo de produto, mercadoria midiática, adquirem um caráter fundamental na formação da imagem dos destinos turísticos. Este tipo de formação interfere diretamente na promoção e no desenvolvimento dos mes mos, através do seu poder de sedução transformando a imagem em um instrumento, capaz de associar sentimentos, emoções, idéias, pré-julgamentos e fatores psicológicos funcionando como fator determinante do sucesso, projeção ou declínio das localidades turísticas e de suas campanhas publicitárias.

No binômio turismo e meios de comunicação de massa, os valores sócios culturais ganham um novo significado frente à mídia, e o uso sistematizado de imagens a torna uma poderosa ferramenta de persuasão. Isto ocorre para Franchi (2004), porque o turismo é uma atividade que vende produtos e serviços através de imagens que fomentam emoções individuais e coletivas.

A mídia é hoje uma das maiores criadoras e propagadoras de modismos, de forma a garantir a aceitação e manutenção de seu público. Imagens de determinados locais ou comportamentos, por exemplo, quando explorados pela TV com intensidade, podem se transformar em ícones momentâneos de negócios turísticos

(Frachi, 2004, p.120).

Contudo, o autor ressalta que esses efeitos apresentam um impacto maior entre os jovens, por estes apresentarem características de experimentadores natos e, portanto buscarem sempre o novo, o diferente e o inusitado. Entretanto os elementos ideológicos de comportamentais propagados pela mídia, como dito anteriormente, são moldados pelo caráter do modismo, e como tal são excludentes e não possuem caráter desenvolvimentista, não consolidando por si só o novo comportamento e consequentemente assumem natureza temporária e passageira, podendo ser desconstruídos com o simples surgimento de um novo modismo.

Baseado nesses aspectos, estratégias e técnicas são utilizados cada vez mais nos meios de comunicação de massa em função da indústria do turismo, com o propósito de atrair e satisfazer o turista por meio de produtos previamente elaborados, apresentados pela mídia de maneira a despertar o desejo e a motivação de viajar, pelo prazer vivenciado através da imagem.

Observando as numerosas variáveis relacionadas à mídia, Bryant e Zillmann (2002) revelam que diversos autores chegaram ao consenso de que ela produz efeitos sociais, contudo as opiniões divergem quanto à forma e intensidade desses efeitos. A forma que a mídia apresenta-se, em especial quando vincula informação e publicidade, sugere uma possível interferência na formação dos valores, das crenças, das mentalidades, enfim, a mídia pode levar a um processo de transformação cultural.

Como resultado da interação dessas ferramentas de marketing, a serviço da mídia para a divulgação dos destinos turísticos, tem-se a identificação da imagem da marca. Esta marca é capaz de mostrar ao público a imagem de um destino turístico - TDI (tourism destination image), que surge como nova estratégia adotada pelos planejadores, para criar uma vantagem competitiva através de uma marca, que serve para criar uma identidade do local.

Construir uma imagem para uma localidade turística demanda tempo e muito investimento. Não se faz da noite para o dia. Muito pelo contrário, é um trabalho árduo de muitos anos de pesquisa e de posicionamento das idéias nas mentes dos turistas. (...) Para criar uma imagem turística é preciso causar impactos positivos, relevantes e de credibilidade, de sorte a fazer penetrar na mente dos turistas atributos que o atraiam a essa localidade

(Trigueiro, 1999, p. 45-46).

A execução bem sucedida da TDI para Pimentel, Pinho e Vieira (2006, p. 289) provocam "impacto no comportamento do consumidor, influenciando na sua decisão de escolha”. Dessa forma, surge um novo paradigma, o turismo produto-espaço, que apresenta o TDI como um de seus elementos, no qual o desenvolvimento do destino depende das características dos produtos para gerar ações capazes de influenciar na organização do espaço, no intuito de atrair a demanda para o destino.

Dessa forma compreendemos que a imagem de um destino é representada como o conjunto de expectativas e percepções que o visitante potencial tem sobre o destino. Estas expectativas e percepções são resultantes das informações repassadas pelas empresas envolvidas no processo, como agências e hotéis, os relatos de amigos ou notícias descritivas veiculadas na mídia, ajudando dessa maneira a desenvolver a imagem (Buhalis, 2000).

Conhecer a imagem que o público tem do local, proporciona identificar falhas na percepção da imagem que o destino quer transmitir, bem como, reconhecer os pontos fracos do destino, facilitando suas correções. Portan- 
to analisar o discurso midiático propagado pelos meios de comunicação, torna-se recurso ímpar para entender se a imagem de Santa Rosa de Lima e da atividade do agroturismo desenvolvida na região está sendo retratada de forma fidedigna, bem como, se a utilização das marcas Acolhida na Colônia e Acceuil Paysan agregam valor ao destino.

\section{Resultados/discussão}

O município de Santa Rosa de Lima fundado em 10 de maio de 1962, por meio da lei $\mathrm{n}^{\circ}$. 823, atualmente conta com uma população de cerca de 2000 habitantes que vivem em um território de aproximadamente 154 $\mathrm{km}^{2}$. Localiza-se na mesoregião sul do Estado de Santa Catarina e situa-se junto às encostas da Serra Geral e do vale do rio Braço do Norte, juntamente com outros 16 municípios que formam a microrregião de Tubarão. Limita-se ao norte com Anitápolis, ao sul com Rio Fortuna, a leste com São Francisco e São Martinho e a oeste com o Rio Fortuna e Urubici . Os colonos alemães que ali chegaram iniciaram um sistema de plantio utilizandose da coivara ou rotação de terras, com o desmatamento de grandes áreas. Nos primeiros anos a plantação era principalmente de milho e abóbora, nos anos seguintes foram incluídos outros cultivos, tais como: mandioca e batata principalmente para a engorda dos porcos e alimentação dos outros animais. E para a subsistência era cultivada a lavoura secundaria com: feijão, batata inglesa, cará, amendoim entre outros (Muller, 2001).

Na década de 60, a Souza Cruz implanta as primeiras estufas de fumo na região, muito embora apenas nos anos 70 começa a se expandir atingindo o seu apogeu nos anos 80. (Paulilo,1990). Com as vantagens oferecidas por intermédio da integração agroindustrial, o fumo trouxe consigo a consolidação da extração da madeira que, segundo Muller (idem, p. 79) na visão dos agricultores era "um ponto positivo, uma vez que deixou de se perder a lenha na lavoura, além de constituir num dos poucos meios de sobrevivência”.

Fruto da exploração indevida dos recursos naturais, decorrente principalmente da fumicultura, Santa Rosa de Lima e os demais municípios das Encostas da Serra Geral, chegaram aos anos 90 com sérios problemas ambientais. Esta realidade diminuiu as possibilidades de sobrevivência econômica das famílias agricultoras, gerando um impacto de cunho social em função do êxodo rural, última opção destas famílias, de obter novas oportunidades nos grandes centros urbanos industrializados (Uller, 2005).

$\mathrm{Na}$ tentativa de reverter esse processo, o movimento agroecológico surge como nova estratégia produtiva e econômica, para os agricultores no município que, em 1996, passam a ter assessoria de professores da Universidade Federal de Santa Catarina (UFSC), do Centro de Estudos e Programação da Agricultura em Grupo (CEPAGRO) e o poder público local. Como resultado, em dezembro desse mesmo ano, é fundada a Associação dos Agricultores Ecológicos das Encostas da Serra Geral (AGRECO), que trazia também como objetivo a disseminação de ideais ambientalistas e sociais, voltados para uma prática de agricultura ética e inclusiva (Muller, 2001; Uller, 2005).

Em conseqüência dessa nova atividade, a cidade passa a receber muitos visitantes interessados em conhecer o modelo agroecológico de formação de agroindústrias, a associação e o trabalho cooperativo desenvolvido na localidade. É desta forma que o turismo emerge gradativamente, embora não existisse ainda infra-estrutura hoteleira e de acesso adequada (Feuser, 2006).

Esse movimento acaba por inserir o agroturismo em Santa Rosa de Lima, tendo por base o modelo da Associação Francesa de Agroturismo Accueil Paysan. Neste modelo de turismo no espaço rural, o turismo é desenvolvimento como uma atividade complementar àquelas realizadas nas propriedades agrícolas, articuladas às suas principais funções que, com o tempo, passam a se constituir em atrativo turístico. Para consolidar este modelo, amplamente discutido em oficinas pelos agricultores interessados, foi criada, em 1999, a Associação de Agroturismo Acolhida na Colônia (AAAC), tornando o Brasil o primeiro destino da América Latina a figurar nos roteiros oficiais da associação francesa Accueil Paysan, que já atuava em dez paises da Europa (Arnhold, 2006).

\section{Circunstâncias de enunciação do material analisado}

O universo de análise deste estudo e as circunstâncias de enunciação do mesmo compreenderam um grupo de 60 (sessenta) matérias de caráter publicitário e jornalístico, publicadas nos últimos cinco anos, enfocando o município de Santa Rosa de Lima e atividades relacionadas ao agroturismo, a Acolhida na Colônia e a Accueil Paysan. Para chegarmos a este universo, realizamos busca eletrônica em bancos de dados da internet de forma aleatória para identificar os formatos mais recorrentes.

Por ocupar um lugar privilegiado de formação e explicação das realidades por meio do discurso propagado, os meios de comunicação em geral, auxiliam na divulgação, antecipando os fatos, sugerindo e modificando as ações dos leitores, substituindo em muitas ocasiões as instituições familiares e educacionais pela mídia no pro- 
cesso de formação de opinião. Partindo do entendimento desse fato, a seleção do material a ser analisado, teve como interesse maior a interpretação dos signos presentes nos discursos de matérias publicadas por veículos que não apresentavam vincúlo direto com entidades relacionadas ao trabalho desenvolvido no município. Neste sentido, a utilização dos sites da Acolhida na $\mathrm{Co}^{-}$ lônia e da AGRECO, foi parte deste universo de análise como ferramenta para traçar um perfil comparativo dos discursos de outras mídias e consequentemente permitirem observar as variações apresentadas pelas demais matérias.

A intensidade, a abrangência e os formatos que a mídia irá utilizar, são determinados pelo grau de interesse na divulgação do assunto e do nível de interesse público em geral sobre o tema. Tais fatores são fortemente evidenciados no material selecionado nesta pesquisa, formando um conjunto de matérias voltadas a um público específico que se interessa por assuntos direcionados a agricultura (agroindústrias/turismo rural), meio ambiente e responsabilidade social locais.

Como conseqüência, este tipo de notícia local, dificilmente ganha destaque na mídia nacional nos meios de comunicação de massa mais acessíveis à população em geral. Dessa forma podemos observar que as notícias ganham um espaço maior na região e à medida que se afasta de Santa Rosa de Lima, passa a ser direcionada para um público restrito com formatos cada vez mais específico ao tema.

\section{Caracterização e dimensão da imagem do agroturismo}

Um dos objetivos da pesquisa, na busca pelos discursos relevantes, que constituem a imagem do agroturismo em Santa Rosa de Lima propagada pela mídia, foi o de caracterizar e dimensionar essa atividade. Para tal utilizamos a seleção do dicionário de base e a partir destas chegamos aos demais elementos do modelo de cooperação textual, apresentados na metodologia. A partir desta 'bricolagem' de palavras e frases verificamos os temas recorrentes nos meios de comunicação que são associados ao discurso do agroturismo. Tais ferramentas proporcionaram destacar as temáticas enfocadas no material selecionado e qual sua relevância, seu engajamento ideológico. E, portanto sua contribuição para a construção da imagem pelos leitores em geral. Não nos cabe, conduzir essa análise, de forma a impor o que é certo ou errado, o que é bom ou mal, uma vez que tais questões estão relacionadas a valores, códigos éticos e morais, que constituem a cultura de cada sociedade.

Aparentemente os itens constituintes do discurso sobre o agroturismo em Santa Rosa de Lima caracteri- zam-se por formarem uma rede de idéias que permeiam umas as outras, formando elos entre os diversos pontos que se justificam exatamente por existirem atreladas umas as outras, unidas por pontos de intercessão. Em outras palavras os elementos que formam o discurso agem num efeito cascata, no qual um fator gera estímulo para o aparecimento do fator seguinte, e assim por diante até voltar para o ponto inicial. A dimensão final é a criação de uma cadeia de dependência entre todos os pontos, ligados a um ponto central que é o agroturismo.

Essa cadeia de elementos explica o discurso sobre o agroturismo, partindo da implantação do modelo de sucesso francês da associação Accueil Paysan, pelos agricultores de Santa Rosa de Lima, que aos 'olhos' da mídia tiveram a oportunidade de planejar uma atividade econômica para o município, a partir de um modelo que já era vencedor. Ainda assim, o que é realizado em SRL é constantemente avaliado por esta mídia, principalmente quando oferta cursos e treinamentos que disponibilizam novos conhecimentos técnicos e científicos aos trabalhadores possibilitando o desenvolvimento local.

É também através dos relatos na mídia, que se fortalece a idéia de que o conhecimento formal aliado ao desenvolvimento local impulsionado pela atividade do agroturismo traz a tona para a população local, as reflexões sobre as questões ambientais e a necessidade da preservação e conservação dos recursos naturais. Neste sentido, as notícias veiculadas demonstram de forma favorável que esse conjunto de fatores transforma o local e melhoram a qualidade de vida da comunidade, pela sua inserção em um processo de discussão de caráter mundial.

Com relação ao agroturismo, a mídia considera que há um dinamismo grande que amplia as relações e cria espaço para novas possibilidades no meio rural. O princípio do agroturismo é mantido ao aliar a agricultura a novas práticas econômicas, e a inclusão de outras pessoas favorece o desenvolvimento de atividades paralelas, que comungam dos mesmos ideais como o ecoturismo e os esportes radicais. A profusão de todos esses acontecimentos atua revertendo o êxodo rural e favorecendo o retorno de muitas pessoas ao município rural em questão. Este retorno ao meio rural e a retomada de suas raízes por muitos dos moradores, nas notícias locais, significa a promoção de um resgate cultural e consequentemente a valorização das tradições, da gastronomia, da dança entre outros elementos, que passam a integrar o novo cenário que se forma.

A inter-relação dos itens do discurso sobre o agroturismo em Santa Rosa de Lima, fecha o ciclo, retornando ao ponto de partida que é o modelo francês. Contudo esse já não é mais o mesmo por que sofreu mudanças 
que o adaptaram em função da realidade local, originando um novo modelo, que se configura como modelo para as demais regiões do país. Na figura a seguir uma síntese destas considerações explanadas (figura 1).

Traçando um perfil a partir do discurso divulgado pela mídia em contraponto com as ações observadas no município de Santa Rosa de Lima, podemos constatar que o processo de implantação do agroturismo na região, através do modelo da Accueil Paysan, apresenta alguns aspectos relevantes, que não são destacados nos meios de comunicação. A escolha deste modelo é apresentada pela mídia de forma a deixar subentendido, como sendo fruto de uma ação conjunta de todos os agricultores, devido ao alto grau de conscientização ambiental. O que não transparece no discurso é que essa escolha foi fruto de alguns atores da comunidade, sendo adotada posteriormente por outros segmentos da população. A implantação do agroturismo teve como objetivo principal garantir possibilidades de sobrevivência da população agrícola e evitar o êxodo rural. A adoção de uma prática que melhor utilizasse os recursos naturais caracterizase como uma ação muito mais de caráter social, do que a tentativa de reverter problemas ambientais, como normalmente é apresentada.
Outra questão que merece atenção está relacionada à apresentação da dinâmica do modelo, na qual as intervenções de resgate cultural são vistas como ações espontâneas. Um modelo que propõem aliar, agricultura orgânica ao turismo, obviamente apresentará os alimentos como destaque, esse recurso utilizado a favor da gastronomia irá valorizá-la e para o desenvolvimento do turismo, ações de melhoria na infra-estrutura e na conservação dos atrativos e do patrimônio são necessários, não configurando assim uma ação ao acaso como transmitida pela mídia.

Por fim, resta uma última observação, os resultados alcançados em Santa Rosa de Lima com a atividade do agroturismo desencadearam a implantação do modelo na região, conferindo uma imagem de sucesso ao modelo, contudo devemos ressaltar que o discurso propagado pela mídia confere a cidade e ao modelo um reforço dessa imagem. A intercessão desses fatores proporciona um estimulo duplo, à medida que o modelo consolida-se e amplia sua área de atuação, maior é seu destaque na mídia. E esta age de forma a aumentar a credibilidade da primeira, aumentando o interesse dos turistas em conhecer o local e impulsionando a expansão das ações da Acolhida na Colônia.

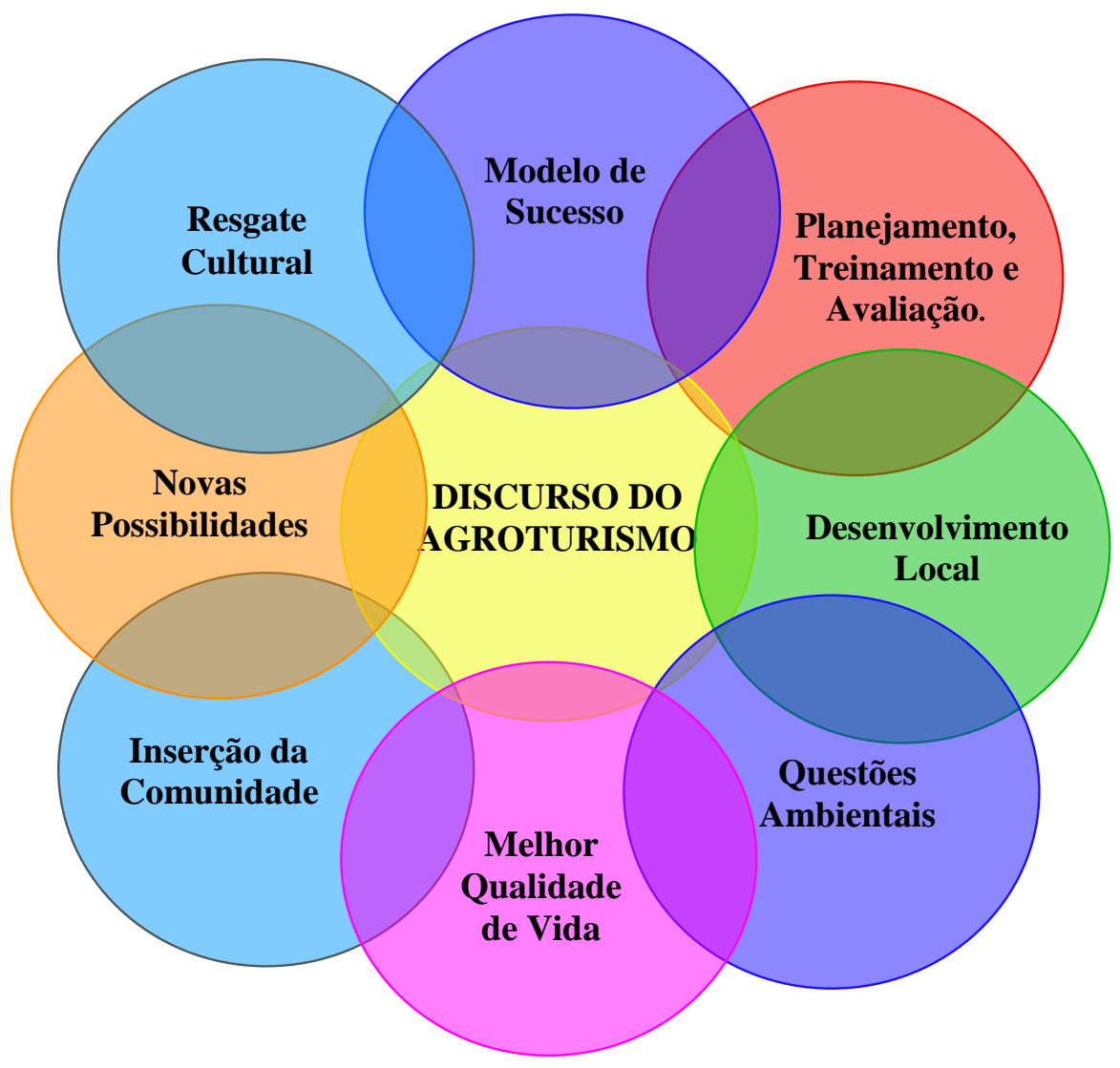

Figura 1: Elementos do Discurso do Agroturismo. Fonte: Os autores 


\section{Variações no discurso midiático}

Com base na análise textual das estruturas de mundo/matrizes de mundo, as atitudes proposicionais são reconhecidas, formando as atribuições de valores de verdade e o juízo de acessibilidade entre mundos. Dessa maneira, nossa reflexão leva ao reconhecimento das variações no discurso midiático sobre o agroturismo em Santa Rosa de Lima. Dois temas centrais dividem o foco de forma alternada e em certos momentos simultaneamente.

O primeiro discurso reconhecido nos textos, fala das motivações e atrativos do município, que é sempre associado à paz e tranqüilidade, local propício para um maior contato com a natureza, tendo como ponto alto a gastronomia, a base de produtos orgânicos e, portanto, alimentos saudáveis.

$\mathrm{O}$ segundo tema aborda as ações que conferem credibilidade ao projeto de agroturismo. A constante realização de cursos, seminários, intercâmbios e treinamentos, além do objetivo de instrumentalizar o agricultor, através do acesso a conhecimentos técnico-científicos, passa ao leitor a idéia que a atividade tem o respaldo de universidades que certificam a qualidade do trabalho, por meio de conhecimento formal. Ainda nesse âmbito, a rede de parcerias com entidades internacionais e órgãos governamentais, apresenta caráter semelhante ao descrito a cima, por proporcionar status e melhoria da imagem da atividade.

Outro fator observado por meio da cooperação textual é a presença de um discurso oculto, ou seja, a presença de um discurso que não se mostra diretamente no texto, mas que se caracteriza por estar subentendido, insinuações não marcadas lingüisticamente no texto, cuja identificação e interpretação dessas informações cabem ao leitor. O movimento de agroturismo de Santa Rosa de Lima, tendo por base o modelo da Associação Francesa de Agroturismo Accueil Paysan, reflete o discurso da importância da marca no sentido da valorização dos produtos e serviços da agricultura familiar e do turismo. Dessa forma as matrizes de mundo presentes nas matérias analisadas destacam os discursos, repassando a ideologia do modelo de agroturismo do município.

\section{Considerações finais}

A mídia ao entreter e informar a população utiliza recursos no intuito de seduzir o público e levá-lo a se identificar com opiniões, atitudes e comportamentos que se adeqüam as ideologias das classes dominantes, induzindo a sociedade aos padrões da sociedade de consumo. Entendendo esse fator, o estudo aqui apresentado foi realizado de modo a identificar a imagem divulgada no discurso midiático sobre a Acolhida na Colônia no contexto do desenvolvimento da atividade do agroturismo em Santa Rosa de Lima. A partir do material selecionado, a análise possibilitou caracterizar e dimensionar o discurso midiático, bem como identificar variações presentes no mesmo.

Durante o processo de coleta de dados algumas dificuldades surgiram em função do material a ser selecionado, caracterizar-se de difícil acesso. Isto porque as matérias relacionadas ao tema abordado são dirigidas a um público muito específico e, portanto encontrado na grande maioria das vezes em veículos direcionados a eles, não se configurando em assunto de debate co $^{-}$ rriqueiro na mídia em geral, contudo, mesmo havendo essas dificuldades, a pesquisa não chegou a ser comprometida.

Os resultados desta investigação proporcionaram uma análise do discurso veiculado pela mídia e suas variações, que se apresenta como uma exaltação de um modelo de sucesso implantado na região, que traz o desenvolvimento local, unindo atividades agrícolas à prática do turismo. De posse desses dados, sua principal contribuição consiste na possibilidade de uma aplicação prática das etapas anteriores dando continuidade ao projeto na elaboração da dissertação, na qual pretendemos observar se a imagem percebida pela imprensa condiz com a que é construída pelos atores sociais envolvidos no processo e dos demais moradores.

A continuidade desse estudo possibilitará um melhor aproveitamento das ferramentas oferecidas pelos meios de comunicação a favor da Associação Acolhida na Colônia, para consolidar a marca, agregar valor a mesma, bem como corrigir possíveis desvios da imagem do agroturismo, em benefício da atividade e de seus organizadores. Contudo devemos ressaltar que a utilização dos recursos midiáticos para a divulgação desse turismo ético e inclusivo, deve ser conduzida de forma a obedecer a esses mesmos valores, evitando uma manipulação da informação visando o lucro pelo lucro. Mais do que informar e divulgar, a mídia estimula novas transformações, a comunidade pode criar seu próprio modo de apropriar-se da cultura de massa, usando a sua cultura como recurso para fortalecer-se e inventar significados, identidades e forma de vida própria.

\section{Referências bibliográficas}

Arnhold, M. (2006) "Turismo Rural Ético: o agroturismo em Santa Rosa de Lima- SC". 2006. 93f. (Dissertação) Mestrado em Turismo e Hotelaria. Centro de Educação Universidade do Vale do Itajaí, Balneário Camboriú.

Bryant, J.; Zillmann, D. (2002) Media Effects: advances in theory and researche. Mahwah: Lawrence Erl- 
baum Associates.

Buhalis, D. (2000) "Marketing the competitive destination of the future". Tourism Management. 21, 97-116.

Carmo, E. S.

2006 "O Espaço do Fenômeno Turístimo no Contexto Atual”. Ruschmann, D.; Solha, K. (Orgs.). Planejamento Tursitico. Barueri: Manole.

Castells, M. (1993) A Era da Informação: economia, sociedade e cultura. Rio de Janeiro: Paz e Terra.

Eco, U. (1986) Lector in Fabula. São Paulo: Perspectivas.

Feuser, L. (2006) "O Agroturismo em Santa Rosa de Lima: itinerários da formação de m turismo sustentável nas Encostas da Serra Geral”. 2006. 96f. (Monografia) Curso de Turismo e Hotelaria. Centro de Educação. Universidade do Vale do Itajaí, Balneário Camboriú.

Franchi, A. C. P. (2004) "O Marketing e os Efeitos Receptivos no Turismo”. In: Dorta, L \& Droguett, J. Midia, Imagens do Turismo: uma proposta de desenvolvimento teórico para as áreas de comunicação $e$ turismo. São Paulo: Textonovo.

Koch, I. V. (1984) "Discurso e Argumentação". Argumentação e Linguagem. São Paulo: Cortez.

Kotler. P. (1995) Marketing Público. São Paulo.

Kovach, B; Rosentiel, T. (2003) Los Elementos del Periodismo. Madrid: Santillana Ediciones Generales.

Marshall, L. (2003) O Jornalismo na Era da Publicidade. São Paulo: Summus.

Muller, J. M. (2001) "Do tradicional ao Agroecológico as Veredas das Tradições: o caso dos agricultores familiares de santa Rosa de Lima/SC". 2001. 207f (Dissertação) Programa de Pós-Graduação em Agroecossistemas, Universidade de Santa Catarina, Florianópolis.

Nielsen, C. (2002) Turismo e Mídia: o papel da comunicação na atividade turística. São Paulo: Contexto.

Noblat, R. (2003) A Arte de Fazer um Jornal Diário. São Paulo: Contexto.

Paulilo, M. I. (1990) Produtor e Agroindústria: consensos e dissensos. Florianópolis: UFSC.

Pimentel, E.; Pinho, T. \& Vieira, A. (2006) "Imagem da Marca de um Destino Turístico". Turismo - Visão e Ação - vol.8, nº. 2, p.283-298, maio/ago. Itajaí: Editora da Univali.

Piovesan, G. C. (2005) "Jornal e Turismo: um campo minado". Congresso Brasileiro De Ciências Da Comunicação, 28, 2005. Rio de Janeiro. Anais... São Paulo: Intercom.

Piza, D. (2003) Jornalismo Cultural. São Paulo: Contexto.

Ruschmann, D. (1990) Marketing Turístico: um enfoque promocional. Campina: Papirus.
Ruschmann, D. (1997) Turismo e Planejamento Sustentável: a produção do meio ambiente. Campinas: Papirus.

Silva, Y. F. (1999) "Cuidando de si ou Violência Corporal? O discurso sobre o envelhecimento na mídia". Florianópolis. 220 f. Tese (Doutorado em Filosofia da Saúde) - Centro de Ciências da Saúde/Programa de Pós-Graduação em Enfermagem, Universidade Federal de Santa Catarina.

Sousa, J. P. (2004) Introdução à Analise do Discurso Jornalístico Impresso: um guia para estudantes de graduação. Florianópolis: Letras Contemporâneas.

Swarbrooke, J. (2000) Turismo Sustentável: conceitos e impacto ambiental. São Paulo: Aleph.

Tahara, M. (1998) Mídia. 7 ed. São Paulo: Global.

Trigueiro, C. M. (1999) Marketing e Turismo: como planejar e administrar o marketing turístico para uma localidade. Rio de Janeiro: Qualitymark.

Tulik, O. (2000) "Do conceito às estratégias para o desenvolvimento do turismo rural". In: Rodrigues, Adyr Balasteri (org.) Turismo e Desenvolvimento Local. 2 ed. São Paulo: Hucitec.

Tulik, O. (2003) Turismo Rural. São Paulo: Aleph.

Turato, E. R. (2003) Tratado da Metodologia da Pesquisa Clínico Qualitativo. Petrópolis: Vozes.

Uller, C. (2005) "O Agroturismo de Santa Rosa de Lima - SC: Características e Singularidades da Hospedagem Familiar”. 2005 (Dissertação) Programa de Pós Graduação Stricto Sensu em Turismo e Hotelaria. Universidade do vale do Itajaí. Balneário Camboriú.

Wild, B. (2004) "Práxis do Turismo: a real transfiguração do espaço". Dorta, L \& Droguett, J. Midia, Imagens do Turismo: uma proposta de desenvolvimento teórico para as áreas de comunicação e turismo. São Paulo: Textonovo.

Recibido:

$01 / 06 / 10$

Reenviado:

$31 / 12 / 10$

Aceptado:

$07 / 01 / 11$

Sometido a evaluación por pares anónimos 